\title{
Web-based Platform for Computer Aided Innovation
}

\section{Combining Innovation and Product Lifecycle Management}

\author{
Nora Dörr ${ }^{1}$, Edda Behnken ${ }^{2}$, and Dr. Tobias Müller-Prothmann ${ }^{3}$ \\ ${ }^{1}$ Pumacy Technologies AG, Germany, nora.doerr@pumacy.de \\ 2 Pumacy Technologies AG, Germany, edda.behnken@pumacy.de \\ ${ }^{3}$ Pumacy Technologies AG, Germany, tobias.mueller-prothmann@pumacy.de
}

\begin{abstract}
Innovation is one of the main drivers of business success. Using computers and special software applications in support of innovations cannot only shorten the whole process of bringing an initial idea to life, but it can improve the overall decision making process. Moreover, aligning innovation management and product life cycle management (PLM) helps organizations in gaining and reusing important knowledge to be one step ahead of the competitors. This chapter provides a practitioner's view on the current situation, deployable solutions, current trends and future developments in the field of computer aided innovation (CAI) and product lifecycle management. A web-based Platform will be illustrated as an example of computer aided innovation.
\end{abstract}

Keywords: innovation management, collaboration, documentation, organization, knowledge management

\section{Introduction}

During the last decade, innovation and the management of innovation have become industry buzz-words. Following Lueke and Katz [1], "[i]nnovation ... is generally understood as the successful introduction of a new thing or method ... Innovation is the embodiment, combination, or synthesis of knowledge in original, relevant, valued new products, processes, or services". Don Sheelen, former CEO of Regina Co., placed innovation at the forefront of modern business stating that: "Innovation is the lifeblood of any organization". He emphasizes, "[w]ithout it, not only is there no growth, but, inevitably, a slow death". And management guru Peter Drucker [2] described it in a quite similar way: "Not to innovate is the single largest reason for the decline of an existing organization". 
But how does a modern way to innovation look like? What is appropriate for today's business life? Which challenges lie ahead and how do we intend to face these challenges?

\section{Background}

Computed aided design (CAD) is already a very well known and highly respected way to work among engineers, architects or designers. Computer aided innovation (CAI) in contrast is a relatively new way to gain a relevant advantage in the market. According to Schumpeter's definition, innovation is a significant, sometimes even radical improvement; either in products, processes or services offered to an internal or external customer of an organization [3].

Some of the most common reasons for failure of innovations are according to O'Sullivan [4]:

- poor leadership,

- poor organization,

- poor communication,

- poor empowerment,

- poor knowledge management.

While the above mentioned reasons are barriers in the cultural infra-structure, other failures happen within the innovation process. These include:

- poor goal definition,

- poor alignment of actions to goals,

- poor participation in teams,

- poor monitoring of results,

- poor communication and access to information.

By taking these failures into account, CAI does not mean the simple use of personal computers within the innovation process. Neither should it imply the use of a computer aided TRIZ-tool nor other models such as provocative word or picture. Rather, it is the goal-oriented adoption of advanced information and communication methods and tools that describes CAI in its current state of development. Major functions of these methods and tools must focus on integration and virtualization as well as interdisciplinary, multi-scalable and multicultural team collaboration. All of these functions are meant to avoid or overcome the innovation barriers described above.

\section{Knowledge management platform}

A web-based platform for knowledge management is an example of software designed to facilitate collaboration and perform specific knowledge management tasks. This platform should provide support to knowledge sharing, communication within and across different types of organizations such as teams, departments, or 
inter-organizational networks. It shall promote active knowledge management of the organization's members to develop new ideas, document existing knowledge, and integrate all aspects of innovation processes. A platform for knowledge and innovation management must provide a basic framework to develop, capture, share, preserve, apply, and evaluate knowledge as presented in Figure 1.

\begin{tabular}{|rl|}
\hline DEVELOP & Creative processes are fostered, ideas emerge, \\
CAPTURE & personal experiences may be stored, and \\
SHARE & shared with colleagues. \\
PRESERVE & For later access, knowledge components are archived, \\
APPLY & integrated in working processes, and \\
EVALUATE & validated. Core knowledge has been identified. \\
\hline
\end{tabular}

Figure 1 Knowledge Management Framework (www.kmmaster.com) ${ }^{1}$

\subsection{Concept}

An ideal platform is based on three central concepts that provide the core of a holistic knowledge management approach and the fundament of a modern innovation management: documentation, organization, and collaboration. Every approach combines these three concepts in a single solution (Figure 2). The precise implementation of these concepts is based on individual characteristics that may vary depending on existing requirements within an organization.

Organization is related to processes, people, roles and the formal organization as presented in an organization chart. Here, the web-based platform supports mapping of organizational and knowledge management processes.

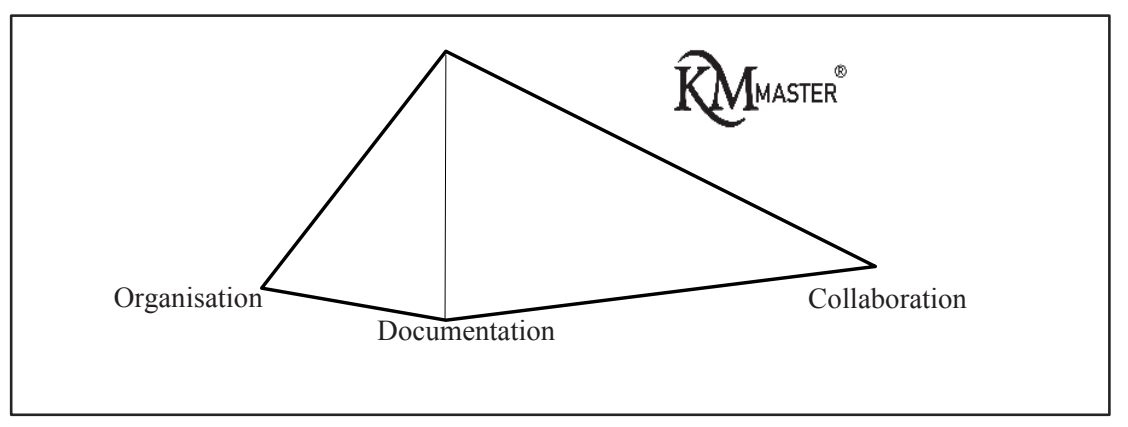

Figure 2 Central Concepts of the KMmaster (www.kmmaster.com)

${ }^{1}$ The KMmaster is a web-based platform developed by Pumacy Systems GmbH. The main goal of the tool is the support of organizations in knowledge based processes (e.g. innovation management). The approach of integrating different fields of interest makes it a unique solution in the area of computer aided innovations. Nevertheless it represents a broader range of tools dedicated to support organizations along the innovation process. 
Documentation is related to structures, documents, data, and classifications. The platform aims at the construction of knowledge components to capture codified knowledge as well as tacit experiences, competencies, and networks.

Collaboration is related to communities of practice, individual motivation, and groupware. The tool supports knowledge and new ideas developed and shared within specialized communities of practice.

\subsection{Task-driven View}

Given a typical task concerning the management of innovations within an organization, the three concepts outlined above can be combined into different approaches. An approach presents a strategy to solve a certain problem. Figure 3 illustrates two approaches to the development of knowledge, competencies, and ideas. They are possible examples from the six knowledge activities introduced in Figure 1. In both approaches the documentation is reduced to a minimum in advantage of the dimension collaboration. The peculiarity of the parameter organization varies.

\begin{tabular}{|l|l|}
\hline \multicolumn{1}{|c|}{ Approach 1 } & \multicolumn{2}{|c|}{ Approach 2} \\
\hline $\begin{array}{l}\text { If collaboration becomes more } \\
\text { intensive and formalised, do you } \\
\text { believe that the innovation process } \\
\text { could be improved and extended? }\end{array}$ & $\begin{array}{l}\text { If knowledge was not documented } \\
\text { and made accessible, an innovation } \\
\text { process in combination with an } \\
\text { intense exchange of experiences } \\
\text { might support a reuse of } \\
\text { knowledge. }\end{array}$ \\
\hline
\end{tabular}

Figure 3 Approaches of a web-based platform - KMmaster-examples (www.kmmaster.com) 
These examples show only two different ways in which the general platform might evolve, always according to the specific needs of the utilizing organization.

\subsection{Functions}

The web-based platform should support internal and external communication as well as virtualization of knowledge, visualization of decision making processes and the ability of teams to cooperate. These functions are connected to a concrete technical level. For each of the three concepts, the framework of the platform shall provide the following functions:

- Documentation of knowledge and experiences:

- flexible templates to capture knowledge components,

- software system integration,

- classification by community and taxonomy,

- full text search including attachments, meta-data and timeframes.

- Organization of processes and knowledge:

- modeling of innovation and knowledge processes,

assignment of user rights and roles,

○ process-based validation of documents.

- Collaboration in knowledge communities:

○ community-based document management,

○ individually configurable workflow management,

- support of distributed teams and sites,

○ collaborative desktop.

\subsection{Innovation Management Edition}

Every generalist platform must provides specialized editions to meet the requirements within different environments and their individual approaches. These editions must be designed with regard to specific applications (lessons learnt, reporting), processes (innovation management) and industries (life science). Though the editions are standalone solutions, they might be adapted and combined according to the requirements of the deploying organization.

An Innovation Management Edition supports the entire idea management process. From generating ideas, their evaluation, up to their documentation, all people, processes, and organizational levels can be included through highly flexible workflows.

As a result from the analysis of the innovation management process concerning the different roles (idea provider, experts, management), this edition provides a functional tool which practically supports de-centralized creation, share, and use of ideas effectively. 
In addition, an ideal Innovation Management Edition provides functionalities to communicate and interact. Teamwork is supported with interchangeable language files, interdisciplinary teams are united via highly flexible community concepts.

The generation of ideas is supported as well as their contribution. Collaborative workflows back the development and enrichment of the generated ideas, while the anonymity of organization members is guaranteed if they wish so. Nevertheless, detailed ratings and assessments filter the relevant and promising ideas from the one with less good prospects. The latter one might be kept in an archive to inspire others and the former will be fostered and enriched.

Systematic analysis, statistics and reporting allow detailed information of management and other stakeholders.

\section{Product Lifecycle Management (PLM)}

Knowledge is one of the most important factors regarding profit realization in innovation management. For instance, companies who pursue to be "first to market" with their products, have the advantage to realize the profits in the initial phases of PLM until the imitators come to the market. PLM is a strategy which enables the companies to bring better products to market faster and provide better support for customers [5]. Therefore, PLM should be integrated in a whole added value of the company.

Crossan et al. [6] predicted the urgent need to enable feed-forward and feedbackward knowledge sharing between the product lifecycle phases. Their framework points out three levels of organizational learning and knowledge management: individual, group and organization. A knowledge management platform affiliates the exchange of all these levels and allows consequently feedforward and feedback processes. The feed-forward process is embedded in the tool itself, as the system and structures are represented. The institutionalized knowledge affects groups and individuals within the organization (feedback process). However, forward and backward learning does not only affect the different levels of learning but might be seen as a suggestion how to use knowledge gained in different projects and products (Figure 4). Forward and backward knowledge sharing across different products illustrates how knowledge might be used across different product lines.

Forward knowledge sharing is already established in many organizations and the learning curve represents the improvements in costs and benefits. Backward knowledge sharing, however, is also of importance as new solutions or new knowledge gained by the development team is given back to management, sales, and support.

The different states of a product should not be seen as autonomous and self sufficient tasks. Rather, each of them is an important share of the wheel. Only with interaction between the different parts the organization will run smoothly. The knowledge gained by idea owner and developers is important not only for 
themselves as the turn to new projects, but it is important for the people working later with the product, and vice versa.

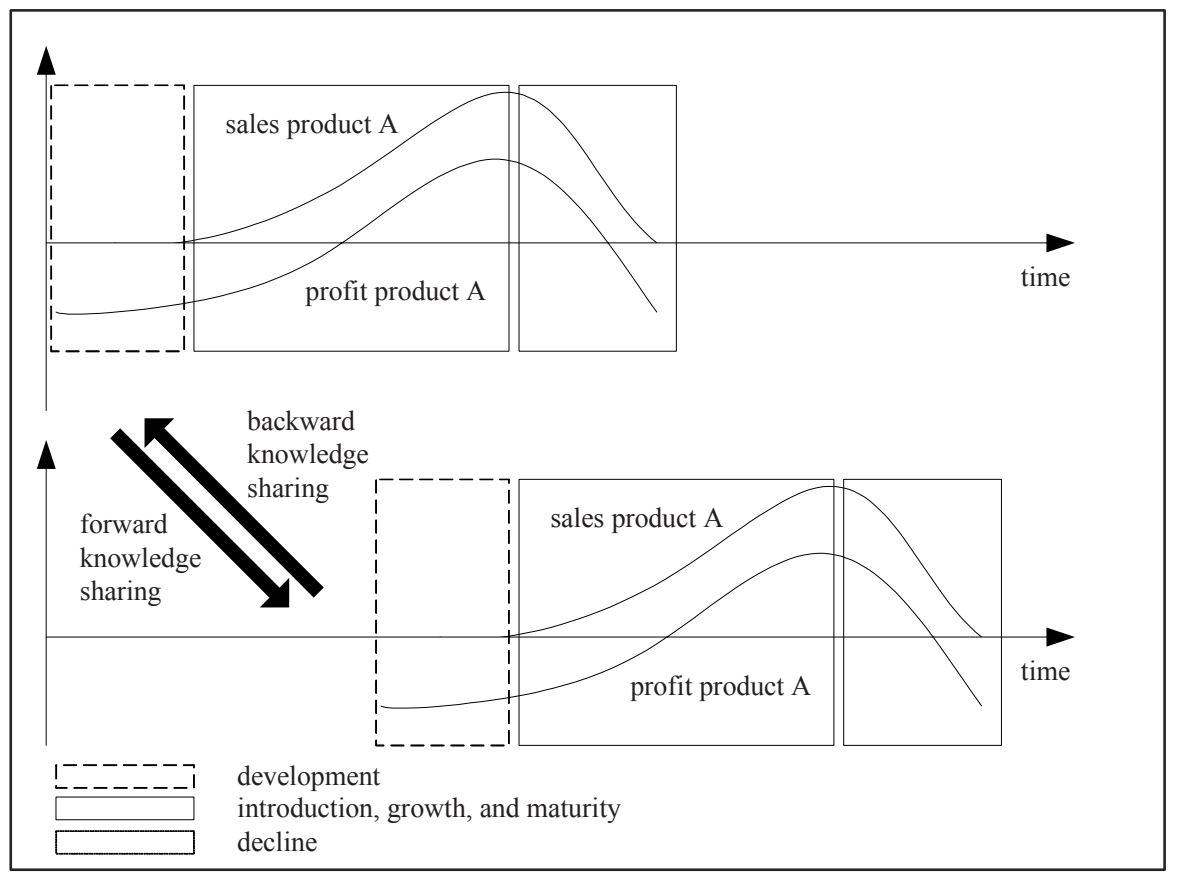

Figure 4 Forward and backward knowledge sharing across different products

Therefore, it is extremely important to integrate the different stakeholders and harvest their knowledge, their ideas, and the successful innovations. A computer based tool which combines organizational, documentary, and collaborative tasks presents a successful approach. According to the organization's needs, it will be modulated with its highly flexible background.

\section{Future Trends}

Commonly, only the individual construction engineer, developer or decisionmaker has the knowledge, why a potential solution has been adopted or abandoned. The goal of every future orientated application must be the externalization of this knowledge and the ac-companying information. The overall view over a product lifecycle is mostly exclusive for the people working on the very project. Nowadays, the reuse of information and knowledge mainly depends on informal networks and communication between the employees [7]. Therefore, it becomes necessary to use specific tools and methods to reuse information throughout the whole PLM process. 
It should be a strategic goal to optimize the process of implementing an innovation, the innovation pace. The quality should be improved and supported by a universal engineering system along the product development process. Innovations must be described formally and systematically and their stage of maturity should be measurable. This will help to improve the quality of innovations and reduce the overall costs. For a systematic innovation process and requirements resulting in reference models, appropriate methods and strategies are needed. This will contribute to make innovations measurable and enable their implementation. The development of these methods and strategies focuses on an integrated risk management to identify product and process risks early on in the development and prepare and plan preventive quality strategies and measurements. Moreover, a dedicated innovation maturity model and an integrated measurement of static and dynamic process parameters to control the processes must be considered. Methods to validate innovations according to quality gates within the innovation implementation process must be gathered. Current trends as Open Innovation and the continuously increasing demand for collaboration lead to additional factors of uncertainty in the management of innovations [8]. Though the decision making process becomes more and more complex, easily applicable evaluation methods must be found and adjusted for the deploying organization [9].

\section{Conclusion}

According to Davila et al. [10] "[i]nnovation, like many business functions, is a management process that requires specific tools, rules, and discipline". An ideal web-based platform shall provide an organization with an easy to use tool. Depending on the specific necessities, it can be implemented as idea or innovation management solution; or even more future orientated using the tool along the whole process of managing a product lifecycle. The necessary rules are integrated into the application and display its backbone. Discipline is supported by special features implemented in the software.

Nevertheless, it is the people of an organization who make the system run. Therefore, it is extremely important to combine not only methods and theories, but to integrate employees and partners as early as possible in the process of deploying a system for computer aided innovation - especially if it is meant to accompany the whole product lifecycle management. 


\section{References}

1. Luecke R., Katz R.: Managing Creativity and Innovation, Harvard Business School Press, Boston (2003).

2. Drucker P. F.: The Essential Drucker: Selections from the Management Work of Peter F. Drucker, HarperBusiness, New York (2001).

3. Schumpeter J.: The Theory of Economic Development, Harvard University Press, Boston (1934).

4. O’Sullivan D.: Framework for Managing Development in the Networked Organisations. Computers in Industry, 47(1), pp. 77-88 (2002).

5. Scheer A. W., Bozsanki M., Muth M., Schmitz W. G., Segelbacher U.: Prozessorientiertes Product Lifecycle Management. Springer, Saarbrücken (2005).

6. Crossan M.: An Organizational Learning Framework: From Intuition To Institution. Academy of Management Rev., 24(3), pp. 522-537 (1999).

7. Müller-Prothmann T.: Leveraging Knowledge Communication for Innovation. Framework, Methods and Applications of Social Network Analysis. In Lang P., Research and Development, Frankfurt (2006).

8. Behnken E.: The Innovation Process as a Collective Learning Process. ICE 2005 Proceedings, pp. 219-226, München (2005).

9. Dörr N.: Entwicklung und Implementierung einer Methode zur anwendungsorientierten Bewertung von Ideen im Rahmen des Ideenmanagements der T-Systems Multimedia Solutions GmbH. HTW Dresden, Dresden (2006).

10. Davila T., Epstein M. J., Shelton R.: Making Innovation Work: How to Manage It, Measure It, and Profit from It. Wharton School Publishing, Upper Saddle River (2006). 